DOI: http://dx.doi.org/10.24093/awejtls/vol1no1.14

\title{
Translating Food Menus from English into Arabic: Linguistic and Cultural Dilemmas
}

\author{
Sultan Mohammed Saaiyed Al- Rushaidi \\ Department of English Language \& Literature \\ Rustaq College of Applied Sciences, Oman \\ Holi Ibrahim Holi Ali \\ Department of English Language \& Literature \\ Rustaq College of Applied Sciences, Oman
}

\begin{abstract}
Translating food menus is a fundamental communication tool for restaurants and coffee shops to market their products and to inform their costumers about the type, quality and diversity of food and products available for their use. This study aims at investigating some translation strategies used to translate food menus from English into Arabic and the salient linguistic and cultural problems resulted fromthe usage of such inappropriate strategies. This study the focuses the translation strategies used to translate food menus in 10 restaurants and coffee shops in Muscat, Oman and the problems which resulted from the usage of such strategies and what could be suggested to help translation practitioners to handle such challenges. The selection of the corpus was based on practical reasons. The data was analysed descriptively by using frequencies and percentages. The findings revealed that there was a number of translation strategies used frequently to translate food menus in the corpus in questions which are: borrowing, literal translation, using a super ordinate word, amplification, reduction and using a load word plus an explanation respectively. The usage of these strategies caused several problems such as lexical ambiguity, lack of clarity and confusion. The study recommends that choosing the appropriate strategy for translating food menu is of a vital importance to help avoiding translation problems. What is the aim of the study?

Keywords: Food terms, translation strategies, culture-specific terms

Cite as: Al- Rushaidi, S.M. \& Ali, H. I. (2017). Translating Food Menus from English into Arabic: Linguistic and Cultural Dilemmas. Arab World English Journal for Translation \& Literary Studies, 1(1).

DOI: http://dx.doi.org/10.24093/awejtls/vol1no1.14
\end{abstract}

